\title{
Frequiência de sarampo, rubéola, dengue e eritema infeccioso entre casos suspeitos de sarampo e rubéola no Estado de Pernambuco, no período de 2001 a 2004
}

\author{
Frequency of measles, rubella, dengue and erythema infectiosum \\ among suspected cases of measles and rubella in the \\ State of Pernambuco between 2001 and 2004
}

\author{
Maria José Couto Oliveira ${ }^{1,2}$, Marli Tenório Cordeiro ${ }^{2,3}$, Fabianni Menezes Costa ${ }^{4}$, \\ Gabriela Murakami ${ }^{4}$, Ana Maria Sinício da Silva ${ }^{2}$, \\ Risalva Correia Travassos ${ }^{2}$ e Vera Magalhães ${ }^{5}$
}

\begin{abstract}
RESUMO
O estudo teve como objetivo verificar a frequiência de sarampo, rubéola, dengue e eritema infeccioso entre casos suspeitos de sarampo e rubéola, no Estado de Pernambuco, Brasil. Foram testadas 1.161 amostras de soro coletadas no período de 2001 a 2004, para as quatro viroses, utilizando-se ensaios imunoenzimáticos para detecção de anticorpos IgM. Desse total, 276 (23,8\%) amostras foram positivas para uma das quatro viroses analisadas. Foram detectados 196 (16,9\%) casos positivos para dengue, 38 (3,3\%) para eritema infeccioso (parvovírus B19), 32 (2,8\%) para rubéola e 10 (0,9\%) para sarampo. Entre os casos suspeitos de sarampo e rubéola, a infecção pelo vírus dengue foi a mais freqüente, seguida pelo parvovírus B19. A semelhança de manifestações clínicas entre as doenças exantemáticas contribui para dificultar o diagnóstico de sarampo, rubéola, dengue e eritema infeccioso, quando observados apenas os critérios clínicos. Deve-se salientar que os quatro testes utilizados foram insuficientes para diagnosticar 76,2\% das doenças febris exantemáticas notificadas. Este é o primeiro estudo que evidencia a circulação de parvovírus B19 humano em Pernambuco.
\end{abstract}

Palavras-chaves: Sarampo. Rubéola. Dengue. Eritema infeccioso. Parvovírus B19.

\begin{abstract}
This study had the aim of investigating the frequency of measles, rubella, dengue and erythema infectiosum among suspected cases of measles and/or rubella in the State of Pernambuco, Brazil. A total of 1,161 serum samples collected between 2001 and 2004 were tested for these four viral diseases, using enzyme immunoassays to detect IgM antibodies. Out of this total, $276(23.8 \%)$ samples were positive for one of the four viral diseases analyzed. There were 196 positive cases (16.9\%) for dengue, 38 (3.3\%) for erythema infectiosum (parvovirus B19), 32 (2.8\%) for rubella and 10 (0.9\%) for measles. Among the suspected cases of measles and rubella, dengue infection was the most frequent, followed by parvovirus B19. The similarity of the clinical manifestations among rash diseases contributes towards making it difficult to diagnose measles, rubella, dengue and erythema infectiosum on clinical grounds alone. It must be emphasized that the four tests used were insufficient for diagnosing $76.2 \%$ of the febrile and rash diseases notified. This is the first study bringing evidence of human parvovirus B19 circulation in Pernambuco.
\end{abstract}

Key-words: Measles. Rubella. Dengue. Erythema infectiosum. Parvovirus B19.

Com a implantação dos Programas Nacionais de Erradicação do Sarampo e Controle da Síndrome da Rubéola Congênita, a positividade dos testes laboratoriais dos casos notificados de sarampo e rubéola no Brasil tem decrescido a cada ano, devido à redução da incidência da rubéola e à interrupção da circulação do vírus do sarampo no país ${ }^{14}$.
Outras doenças exantemáticas, como o eritema infeccioso e o exantema súbito, estão sendo possivelmente confundidas com o sarampo e a rubéola, evidenciando a pouca acurácia do diagnóstico de doenças exantemáticas, quando utilizado apenas o critério clínico ${ }^{1719}$. Possivelmente o mesmo ocorre com o dengue, nas regiões onde há circulação desse vírus ${ }^{14}$.

\footnotetext{
1. Programa de Pós-Graduação em Medicina Tropical da Universidade Federal de Pernambuco, Recife, PE. 2. Laboratório Central de Saúde Pública, Secretaria de Saúde do Estado de Pernambuco, Recife, PE. 3. Laboratório de Virologia e Terapia Experimental, Centro de Pesquisas Ageu Magalhães, Fundação Oswaldo Cruz, Recife, PE. 4. Gerência Geral de Vigilância em Saúde, Secretaria de Saúde do Estado de Pernambuco, Recife, PE. 5. Departamento de Medicina Tropical da Universidade Federal de Pernambuco, Recife, PE. Endereço para correspondência: Dra. Maria José Couto Oliveira. Setor de Virologia/Laboratório Central de Saúde Pública de Pernambuco. Praça Oswaldo Cruz s/n, Boa Vista, 50050-210 Recife PE. Brasil.

Telefax: 5581 3181-6340.

e-mail: mariajosecouto@hotmail.com

Recebido para publicação em 05/03/2008

Aceito em 05/08/2008
} 
O eritema infeccioso, cujo agente etiológico é o parvovírus B19, descoberto em $1975^{1}$, apresenta uma sintomatologia semelhante à da rubéola. A transmissão geralmente ocorre por via respiratória, mas também pode se dar por transfusão de sangue e hemoderivados ${ }^{12}$, especialmente pelo Fator VIII e concentrado de Fator $\mathrm{IX}^{27}$, além da transmissão vertical ${ }^{23}$. Não foram encontrados na literatura, dados sobre a circulação de parvovírus no Estado de Pernambuco.

Com relação ao dengue, apenas uma pequena parcela dos casos apresenta exantema, contudo também é confundida com as demais doenças exantemáticas. Em Pernambuco, a incidência da doença passou de 134 casos/100.000 habitantes em 1995, para 1.438/100.000 habitantes em 2002, como consequiência de grande dispersão da doença no estado ${ }^{4}$.

De acordo com o atual fluxograma estabelecido pelo Ministério da Saúde, nos estados onde há circulação do dengue, o diagnóstico diferencial para esse agravo deverá ser feito em todos os casos suspeitos de sarampo e rubéola, cuja sorologia seja negativa para as duas doenças. Em casos de surtos, se os resultados dos exames para sarampo, rubéola e dengue forem negativos, deverá ser realizado o teste para parvovírus B19, e em menores de 2 anos, o teste para herpesvírus humano tipo $6^{15}$.

Considerando-se a importância do diagnóstico laboratorial para esclarecer a etiologia das doenças exantemáticas virais, e pelo fato de não haver dados na literatura sobre a circulação do parvovírus B19 em Pernambuco, o presente estudo se propôs a investigar laboratorialmente a presença dos vírus do sarampo, rubéola, dengue e eritema infeccioso, nas amostras de soros de pacientes notificados como casos de sarampo e rubéola durante o período de 2001 a 2004, no Estado de Pernambuco.

\section{MATERIAL E MÉTODOS}

Desenho do estudo. Estudo descritivo, do tipo transversal.

População do estudo. Pacientes com febre e exantema e diagnóstico clínico de sarampo ou rubéola, do estado de Pernambuco, atendidos no período de 2001 a 2004, e cujas amostras de sangue foram encaminhadas ao Setor de Virologia do Laboratório Central de Saúde Pública de Pernambuco (LACEN$\mathrm{PE}$ ), tendo a coleta de sangue sido efetuada entre o $5^{\circ}$ e o $28^{\circ}$ dia após o início do exantema.

Definição de casos suspeitos. Os casos suspeitos de sarampo e rubéola foram definidos de acordo com critérios do Ministério da Saúde ${ }^{10}$.

Processamento e análise de dados. As informações dos pacientes foram obtidas das fichas de encaminhamento das amostras ou da ficha epidemiológica. 0 processo de digitação dos dados foi realizado por meio de dupla entrada. Na busca das associações entre as variáveis, foi utilizado o teste do $\chi^{2}$ (qui-quadrado) de Pearson com correção de Yates e, quando necessário, o qui-quadrado de Fisher. 0 nível de significância foi de $95 \%(\mathrm{p}<0,05)$. Software utilizado: EPIINFO versão 6.04 .

Coleta e armazenamento das amostras. No período do estudo, foram recebidas 2.470 amostras de soro de pacientes com febre e exantema residentes no Estado de Pernambuco, com suspeita clínica de sarampo ou rubéola, para confirmação laboratorial, realizado através de ensaios imunoenzimáticos (ELISA) específicos. 0 sangue foi colhido em tubo sem anticoagulante, e após centrifugação e separação do soro, a amostra foi conservada em freezer a $-20^{\circ} \mathrm{C}$ até a realização dos testes. As amostras vinham acompanhadas das suas respectivas fichas de encaminhamento ou fichas epidemiológicas devidamente preenchidas. De acordo com as informações contidas nas fichas, foram selecionadas 1.161 amostras que atendiam aos critérios de inclusão do estudo.

Diagnóstico laboratorial. Os soros dos pacientes suspeitos de sarampo foram testados inicialmente para este vírus, e também para o vírus da rubéola, mesmo os que haviam sido positivos para sarampo. Os soros negativos para os dois agravos, foram testados para o dengue, e, se negativos, testados então para parvovírus B19. Os soros dos pacientes suspeitos de rubéola foram testados inicialmente para o vírus da rubéola, e, se negativos, testados para 0 vírus do sarampo. Os soros negativos para os dois agravos, foram testados para o dengue, e, se negativos, testados então para o parvovírus B19.

Para a detecção de IgM específica foi utilizado o ensaio imunoenzimático de captura de IgM, do tipo sanduíche. Para sarampo e rubéola foram utilizados os kits da DADE-BEHRING (Enzygnost ${ }^{\circledR}$ antimeasles vírus/IgM e Enzygnost ${ }^{\circledR}$ anti-rubella vírus/IgM). Para o diagnóstico de dengue utilizou-se kit produzido por Bio-Manguinhos (EIE-IgM-DENGUE) e para o diagnóstico de eritema infeccioso foi empregado o kit da BIOTRIN (parvovirus B19 IgM Enzyme Immunoassay). Os testes foram processados de acordo com o protocolo recomendado pelos fabricantes.

\section{RESULTADOS}

Do total de 1.161 amostras, 276 (23,8\%) foram positivas para um dos quatro agravos investigados. Das 276 amostras com diagnóstico laboratorial definido, 10 (0,9\%) apresentaram IgM positiva para o vírus do sarampo, 32 (2,8\%) para rubéola, $38(3,3 \%)$ para o parvovírus B19 humano e $196(16,9 \%)$ para 0 vírus dengue. Ficaram sem diagnóstico, 885 (76,2\%) amostras, sendo uma indeterminada para rubéola e outra indeterminada para sarampo. Três amostras foram positivas simultaneamente para sarampo e rubéola e duas foram positivas para rubéola e dengue. Estas cinco amostras foram incluídas na análise. 0 total de positividade foi decrescendo a cada ano: 30,5\% em 2001, 26,7\% em 2002, 19,2\% em 2003 e 11,8\% em 2004.

Entre as doenças analisadas, a mais freqüente foi o dengue, com um percentual de $71 \%$, seguindo-se o eritema infeccioso (13,8\%), a rubéola (11,6\%) e o sarampo (3,6\%) (Figura 1). 0 número decrescente de casos positivos para os vírus analisados, no período de 2001 a 2004, está exposto na Figura 2.

A associação entre o sexo e a positividade de IgM para as doenças exantemáticas analisadas durante o período do estudo, não mostrou diferença significativa (Tabela 1). Dos 10 casos com IgM positiva para o vírus do sarampo, quatro ocorreram entre 


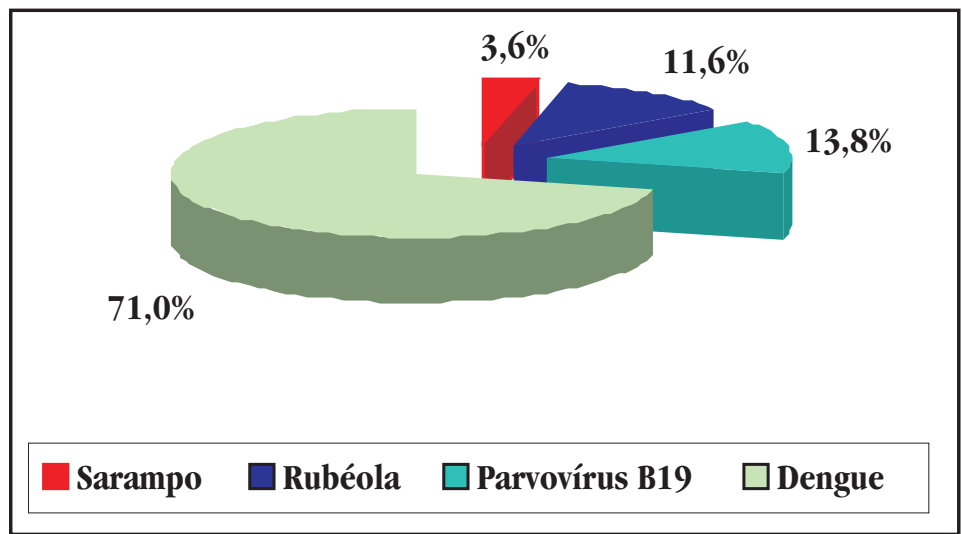

Figura 1 - Percentual de positividade entre os quatro agravos analisados, a partir de casos suspeitos de sarampo e rubéola no estado de Pernambuco, no período de 2001 a 2004.

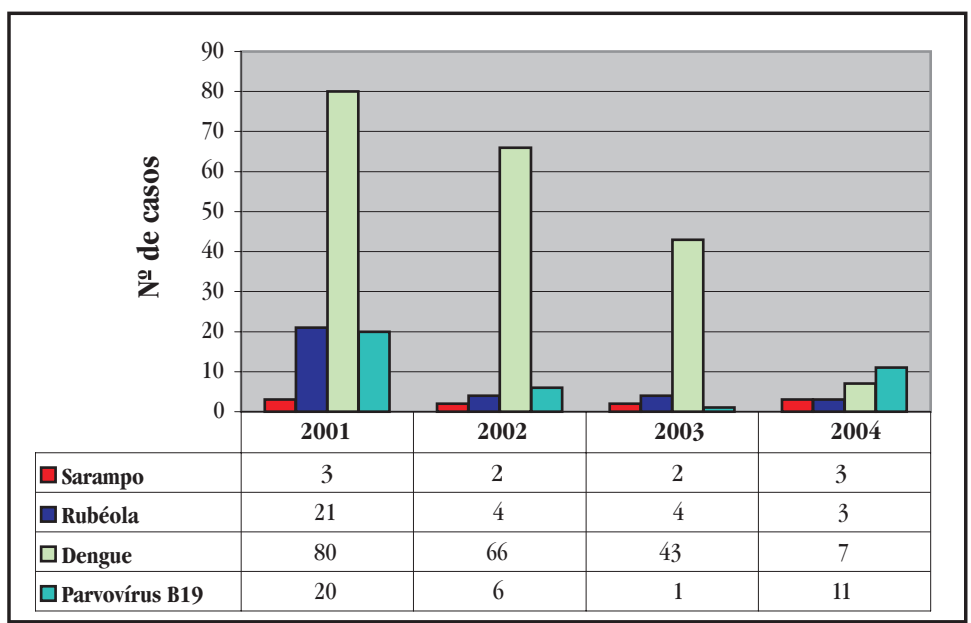

Figura 2 - Distribuição anual das doenças exantemáticas diagnosticadas laboratorialmente, a partir de casos suspeitos de sarampo e rubéola no Estado de Pernambuco, no período de 2001 a 2004.

Tabela 1- Associação entre o sexo e a freqüência de doenças exantemáticas diagnosticadas laboratorialmente a partir de casos suspeitos de sarampo e rubéola, no Estado de Pernambuco, no período de 2001 a 2004.

\begin{tabular}{|c|c|c|c|c|c|}
\hline \multirow[b]{3}{*}{ Sexo } & \multicolumn{4}{|c|}{ Resultado da sorologia } & \multirow[b]{3}{*}{ p-valor } \\
\hline & \multicolumn{2}{|c|}{ positivo } & \multicolumn{2}{|c|}{ negativo } & \\
\hline & $\mathrm{n}^{\underline{0}}$ & $\%$ & $\mathrm{n}^{0}$ & $\%$ & \\
\hline Sarampo & & & & & $0,211^{*}$ \\
\hline masculino & 06 & 60,0 & 459 & 39,9 & \\
\hline feminino & 04 & 40,0 & 692 & 60,1 & \\
\hline Rubéola & & & & & 0,660 \\
\hline masculino & 14 & 43,8 & 450 & 39,9 & \\
\hline feminino & 18 & 56,3 & 678 & 60,1 & \\
\hline Dengue & & & & & 0,689 \\
\hline masculino & 76 & 38,8 & 389 & 40,3 & \\
\hline feminino & 120 & 61,2 & 576 & 59,7 & \\
\hline Eritema infeccioso & & & & & 0,351 \\
\hline masculino & 18 & 47,4 & 447 & 39,8 & \\
\hline feminino & 20 & 52,6 & 675 & 60,2 & \\
\hline
\end{tabular}

Fonte: SES- PE/LACEN * qui-quadrado de Fisher menores de 1 ano (4/10), cinco até 4 anos (5/10), e um (10\%) caso numa paciente de 47 anos. 0 maior número de casos positivos para rubéola ocorreu na faixa etária de 1 a 4 anos (13/32), seguida da faixa de 20 a 39 anos (8/32). Entre os casos positivos para parvovírus B19, a faixa etária mais atingida foi a de 5 a 9 anos (15/38), seguida da faixa de 1 a 4 anos (8/38). Quanto aos casos com IgM positiva para dengue, estes predominaram em crianças de 1 a 4 anos (56/196), seguidos pela faixa etária de 20 a 39 anos (53/196) (Tabela 2).

A confirmação de casos de rubéola foi maior nos meses de outubro (5/32) e novembro (7/32) e de dengue no período de janeiro a junho (137/196), enquanto o eritema infeccioso foi mais freqüente nos meses de agosto (8/38), setembro (7/38) e janeiro (6/38) (Figura 3).

Detectou-se a circulação de parvovírus B19, em 23 municípios de Pernambuco, predominando em Caruaru (6), Recife (6), Garanhuns (3), Jaboatão (3) e Santa Cruz do Capibaribe (2). 0 vírus esteve presente em mais 18 municípios. Três dos casos positivos para parvovírus B19, tiveram hipótese diagnóstica de sarampo. 


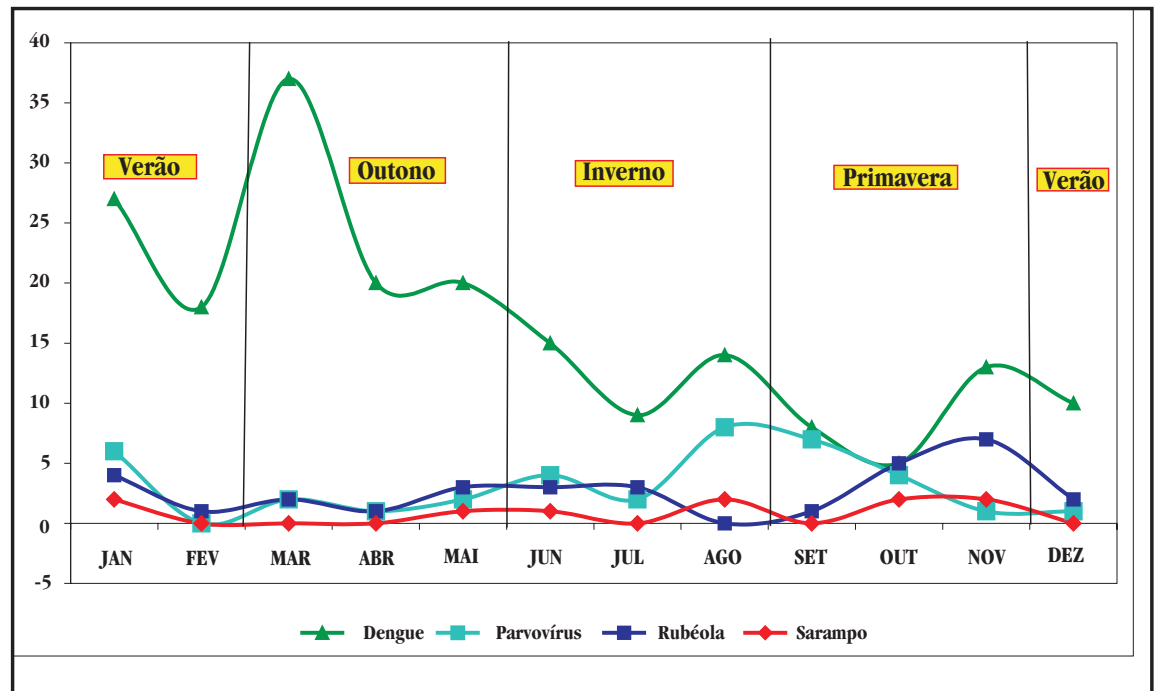

Figura 3 - Distribuição mensal das doenças exantemáticas, a partir de casos suspeitos de sarampo e rubéola no Estado de Pernambuco, no período de 2001 a 2004.

Tabela 2 - Associação entre a faixa etária e a freqüiência de doenças exantemáticas diagnosticadas laboratorialmente a partir de casos suspeitos de sarampo e rubéola no Estado de Pernambuco, no período de 2001 a 2004.

\begin{tabular}{|c|c|c|c|c|c|}
\hline \multirow[b]{3}{*}{ Faixa etária (ano) } & \multicolumn{4}{|c|}{ Resultado da sorologia } & \multirow[b]{3}{*}{ p-valor } \\
\hline & \multicolumn{2}{|c|}{ positivo } & \multicolumn{2}{|c|}{ negativo } & \\
\hline & $\overline{n^{0}}$ & $\%$ & $\mathrm{n}^{0}$ & $\%$ & \\
\hline Sarampo & & & & & $0,129^{*}$ \\
\hline$<1$ & 4 & 40,0 & 247 & 21,5 & \\
\hline $1 \mathrm{a} 4$ & 5 & 50,0 & 369 & 32,1 & \\
\hline $5 \times 9$ & 0 & 0,0 & 186 & 16,2 & \\
\hline 10 a 14 & 0 & 0,0 & 84 & 7,3 & \\
\hline 15 a 19 & 0 & 0,0 & 59 & 5,1 & \\
\hline 20 a 39 & 0 & 0,0 & 182 & 15,8 & \\
\hline$\geq 40$ & 1 & 10,0 & 24 & 2,1 & \\
\hline Rubéola & & & & & 0,010 \\
\hline$<1$ & 1 & 3,1 & 250 & 22,2 & \\
\hline $1 \mathrm{a} 4$ & 13 & 40,6 & 360 & 31,9 & \\
\hline $5 \times 9$ & 4 & 12,5 & 182 & 16,1 & \\
\hline 10 a 14 & 1 & 3,1 & 83 & 7,4 & \\
\hline 15 a 19 & 5 & 15,6 & 54 & 4,8 & \\
\hline 20 a 39 & 8 & 25,0 & 174 & 15,4 & \\
\hline$\geq 40$ & 0 & 0,0 & 25 & 2,2 & \\
\hline Dengue & & & & & 0,000 \\
\hline$<1$ & 15 & 7,7 & 236 & 24,5 & \\
\hline $1 \mathrm{a} 4$ & 56 & 28,6 & 318 & 32,9 & \\
\hline $5 \times 9$ & 26 & 13,3 & 160 & 16,6 & \\
\hline 10 a 14 & 17 & 8,7 & 67 & 6,9 & \\
\hline 15 a 19 & 19 & 9,7 & 40 & 4,1 & \\
\hline 20 a 39 & 53 & 27,0 & 129 & 13,4 & \\
\hline$\geq 40$ & 10 & 5,1 & 15 & 1,6 & \\
\hline Eritema infeccioso & & & & & 0,001 \\
\hline$<1$ & 3 & 7,9 & 248 & 22,1 & \\
\hline $1 \mathrm{a} 4$ & 8 & 21,1 & 366 & 32,6 & \\
\hline $5 \times 9$ & 15 & 39,5 & 170 & 15,2 & \\
\hline 10 a 14 & 5 & 13,2 & 79 & 7,0 & \\
\hline 15 a 19 & 1 & 2,6 & 58 & 5,2 & \\
\hline 20 a 39 & 6 & 15,8 & 176 & 15,7 & \\
\hline$\geq 40$ & 0 & 0,0 & 25 & 2,2 & \\
\hline
\end{tabular}

Fonte: SES-PE/LACEN * qui-quadrado de Fisher

\section{DISCUSSÃo}

0 presente estudo reafirmou uma situação já esperada sobre a interrupção da transmissão do vírus do sarampo no Estado de Pernambuco. Todos os casos (10/1.161) com a IgM positiva para este agravo corresponderam a pacientes vacinados recentemente, o que provavelmente vincula 0 exantema a uma reação vacinal. Reforça essa idéia, o fato de que em três deles houve positividade simultânea para sarampo e rubéola após vacinação com a dupla viral ou tríplice viral.

Convém lembrar que o método imunológico evidencia de forma indireta a presença de infecção, devendo ser avaliado levando-se em consideração alguns critérios, como a clínica do paciente e a conversão sorológica para o vírus envolvido. Durante o estudo foi vivenciada uma situação que comprova essa afirmação.

Em outubro de 2004, deu entrada no LACEN-PE o soro de uma criança de dez meses para confirmação do diagnóstico clínico de rubéola, cujo resultado foi IgM negativa para rubéola e positiva para sarampo. Enquanto se aguardava o período para se coletar a segunda amostra foi realizada a busca por outros casos de sarampo e pelo caso índice. A presença de IgM positiva só para sarampo, com confirmação do Laboratório de Referência Nacional e a informação da genitora de que a criança não havia sido vacinada contra a doença, indicava tratar-se de um caso de sarampo. Na segunda amostra de sangue da criança, coletada na fase de convalescença, a detecção de IgM desta vez foi positiva para os dois vírus, sendo que, ao se realizar a pesquisa de $\operatorname{IgG}$ nas amostras pareadas, evidenciou-se a soroconversão para sarampo e rubéola. Constatouse posteriormente que a criança fora vacinada recentemente com a tríplice viral (antes de 1 ano de idade).

0 fato da primeira amostra de soro ter sido positiva para sarampo e negativa para rubéola, está de acordo com Dietz e cols ${ }^{7}$ sobre a confirmação laboratorial de casos suspeitos de sarampo em situação de baixa transmissão da doença, onde se demonstra que alguns indivíduos vacinados com a dupla viral 
(sarampo e rubéola) ou tríplice viral (sarampo, caxumba e rubéola) podem ter um resultado positivo para sarampo e negativo para rubéola. Tal situação deve-se ao fato de que a resposta de IgM para rubéola após a vacinação é mais lenta que a do sarampo. Portanto, a presença de IgM específica numa única amostra de soro, não comprova a infecção natural pelo vírus do sarampo.

Em Pernambuco, a vacina dupla viral (sarampo e rubéola) foi implantada no ano 2000 destinada ao público de 1 a 11 anos. Em novembro de 2001, com o objetivo de prevenir e controlar a síndrome da rubéola congênita, a campanha teve como público alvo mulheres em idade fértil na faixa etária de 12 a 34 anos. As campanhas, junto com a vacinação de rotina, justificam a baixa frequiência dessa doença no período analisado.

No entanto, o presente estudo mostrou que o maior número de casos de rubéola ocorreu entre crianças de 1 a 4 anos, sugerindo uma associação estatisticamente significativa em relação à faixa etária $(\mathrm{p}=0,010)$, e que não houve associação significativa entre os sexos $(\mathrm{p}=0,660)$. Esses dados, por não corresponderem a uma amostra da população geral, podem não refletir o seu real estado imunitário.

Em dois pacientes foram detectadas simultaneamente IgM para rubéola e dengue. Sabe-se que os anticorpos IgM para rubéola podem ser detectados por um período de 4 a 6 semanas após o exantema, enquanto os do dengue podem persistir por cerca de 70 a 90 dias após a infecção ${ }^{10}$. Em um dos casos, a vacina dupla viral tinha sido aplicada recentemente, sugerindo uma infecção recente pelo vírus da rubéola devido a uma reação vacinal e que a infecção por dengue tenha ocorrido, de forma inaparente, nos últimos três meses. 0 outro caso não tinha história de vacina recente, sugerindo que pode ter ocorrido uma das seguintes hipóteses: infecção nos últimos três meses pelo vírus dengue e infecção recente pelo vírus da rubéola, uma co-infecção, ou reação cruzada entre os dois ensaios de ELISA. Por se tratar de um estudo retrospectivo, não foi possível se obter uma segunda amostra de sangue para esclarecer, através de soroconversão da IgG, qual foi o vírus responsável pela infecção recente. Esse achado reforça a necessidade da coleta de duas amostras pareadas de soro em todos os casos de IgM positiva para sarampo e/ou rubéola ${ }^{14}$.

Ainda em relação à rubéola, não foi observada uma diferença significativa da frequiência dos casos positivos entre o primeiro e o segundo semestre dos anos de 2001 a 2004, como foi evidenciado no Espírito Santo por Cubel e cols ${ }^{5}$ e em Niterói por Oliveira e cols ${ }^{20}$, onde a rubéola foi mais freqüente no segundo semestre. É possível que a análise do referido agravo tenha sido prejudicada pelo alto percentual de reação pós-vacinal, embora também tenha sido observado um discreto pico nos meses de outubro e novembro.

Entre os casos positivos para um dos quatro vírus analisados, 0 maior percentual foi de dengue (71\%). Este resultado era previsto, pois durante o período do estudo houve grande circulação desse vírus no Estado de Pernambuco, principalmente no período de 2001 a 2003, quando foram notificados 124.092 casos de dengue $^{4}$. Durante o período, houve circulação dos sorotipos 1 , 2 e 3 , com predominância do sorotipo $3^{4}$.
Apesar do maior número de casos de dengue ter ocorrido no sexo feminino, quando realizado o teste qui-quadrado de Pearson, não foi observada associação estatisticamente significativa entre os sexos $(\mathrm{p}=0,738)$. Esse achado concorda com os grupos de Figueiredo ${ }^{9}$ e Gonçalves Neto ${ }^{11}$ que também não observaram diferença entre os sexos nos casos de dengue em Manaus e São Luiz, ao contrário do que foi observado no Estado do Pará ${ }^{2}$ onde 0 risco de transmissão foi maior entre as mulheres. Houve diferença estatisticamente significante entre as faixas etárias, sendo a de 1 a 4 anos mais atingida, seguida pela de 20 a 39 anos $(\mathrm{p}=0,000)$. Mais uma vez, esta observação talvez derive de que os soros estudados dos pacientes suspeitos de sarampo e rubéola não representem a população geral. Constatou-se um maior número de casos no primeiro semestre, concordando com o que está descrito na literatura e conforme foi observado nas Cidades de Niterói ${ }^{20}$ e Manaus 9 .

O diagnóstico laboratorial de eritema infeccioso foi 0 segundo mais frequiente entre os quatro analisados, no presente estudo, respondendo por 13,8\% (Figura 1). 0 percentual de positividade de 3,3\% para o parvovírus B19 entre casos suspeitos de sarampo e rubéola foi um pouco maior em relação aos 2,5\% obtidos no Rio de Janeiro e Espírito Santo 5 . Entretanto, foi inferior aos $20 \%$ obtidos pelo grupo de Davidkin ${ }^{6}, 17 \%$ obtidos por Ramsay e cols ${ }^{22}, 14,5 \%$ observados por Wermelinger e cols ${ }^{26} \mathrm{e}$ $6,8 \%$ obtidos por Shirley e cols ${ }^{25}$. Este foi o primeiro estudo que evidenciou a circulação de parvovírus B19 em Pernambuco. Não houve associação estatisticamente significativa entre os sexos, em desacordo ao que foi observado em Manaus ${ }^{8}$ onde predominou no sexo masculino (81\%). Entretanto, foi observado entre os adultos um número maior de casos do sexo feminino em concordância com os grupos de Oliveira ${ }^{17}$ e Figueiredo ${ }^{8}$. Houve uma associação estatisticamente significativa em relação à faixa etária $(\mathrm{p}=0,001)$, sendo a mais atingida a de 5 a 9 anos seguida da faixa de 1 a 4 anos, semelhante ao que aconteceu no estudo de Oliveira e cols ${ }^{18}$. Quanto à distribuição temporal (Figura 3), apesar de Pernambuco não ter as estações climáticas bem definidas, curiosamente, o maior número de casos ocorreu no final do inverno, na primavera e início do verão, de acordo com as descrições de Brown ${ }^{3}$ e Ramsay e cols ${ }^{22}$.

Não foi observada positividade simultânea entre o ensaio utilizado para o diagnóstico de parvovirose e os demais ensaios utilizados nos diagnósticos de sarampo, rubéola e dengue, sugerindo baixo índice de reação cruzada entre as viroses. Reforça essa idéia, o fato de que 11 das 38 amostras com IgM positiva para parvovírus B19 analisadas no Instituto Adolfo Lutz (São Paulo) tiveram o diagnóstico confirmado pela reação em cadeia da polimerase.

Os resultados obtidos no estudo sugerem que a parvovirose em Pernambuco tenha um padrão cíclico de ocorrência (Figura 2), conforme descrito na literatura. Verificou-se maior número de casos em 2001, tendo decrescido em 2002 e 2003, voltando a elevar-se em 2004, com um percentual de positividade de $4,9 \%, 2 \%, 0,4 \%$ e 5,4\%, respectivamente. Para que esta hipótese seja confirmada são necessários estudos complementares por um período de tempo mais longo que quatro anos, uma vez que, segundo Zellman ${ }^{28}$, o ciclo pode ser de 4 a 7 anos. 
Não foi observada a ocorrência de surto de eritema infeccioso no período do estudo, apesar de sua característica ocorrência epidêmica ${ }^{14}$ e nem detectada relação entre os casos positivos. É importante lembrar que 20 a $30 \%$ das infecções pelo parvovírus B19 ocorrem de forma assintomática ${ }^{24}$. Dos 23 municípios de Pernambuco onde foi detectada a presença do vírus, Caruaru e Recife apresentaram o maior número de casos, seguidos de Jaboatão e Garanhuns, e de Santa Cruz do Capibaribe. É difícil avaliar se a circulação viral realmente foi maior nas referidas cidades, ou se a vigilância epidemiológica desses municípios estava mais sensível ao programa das doenças exantemáticas.

Observou-se que 92,1\% dos casos positivos para parvovírus e 90,8\% dos casos positivos para o vírus dengue tinham como hipótese diagnóstica a rubéola.

0 alto percentual de doenças exantemáticas sem a etiologia definida (76,2\%), aponta para a possibilidade de outras doenças serem determinantes do exantema ou a amostra de sangue ter sido coletada numa fase precoce da infecção, quando ainda não havia IgM circulante. 0 fato de mais de $50 \%$ dos casos suspeitos de sarampo e rubéola terem ocorrido em menores de 5 anos, associado ao conhecimento através da pesquisa de Linhares e cols ${ }^{13} \mathrm{da}$ alta prevalência do herpesvírus tipo 6 em crianças do Recife e região metropolitana, sugerem que esse agravo pode ser um dos responsáveis pelos casos que ficaram sem definição diagnóstica. Estudo realizado em crianças recém-vacinadas contra sarampo em São Paulo verificou que o herpesvírus tipo 6 foi responsável por 76,5\% dos casos atribuídos a efeitos colaterais da vacina contra o sarampo, seguido do parvovírus B19 $(17,6 \%)^{16}$, reforçando a idéia de como é difícil o diagnóstico quando utilizado apenas o critério clínico. Devido às precárias condições sanitárias da região, é provável que os enterovírus também sejam responsáveis por uma parte desses casos ${ }^{14}$.

Da mesma maneira que o sarampo e a rubéola são confundidos com outras doenças exantemáticas, o inverso também ocorre. Durante epidemia de dengue em Manaus, foram detectados casos positivos para sarampo, rubéola e parvovirose ao se testar amostras que haviam sido negativas para dengue 9 Em estudo realizado em Niterói, detectaram-se casos de sarampo e rubéola a partir de pacientes com hipótese diagnóstica de dengue, eritema infeccioso e exantema súbito (S Oliveira: comunicação pessoal).

Baseado nos resultados deste estudo é importante que o diagnóstico diferencial seja implementado nos casos das doenças exantemáticas, para que outros agravos possam ser mais bem investigados, norteando permanentemente o sistema de vigilância e apoiando devidamente a rede de atenção à Saúde.

\section{AGRADECIMENTOS}

A Dra. Maria Isabel Oliveira, do Instituto Adolfo Lutz em São Paulo, por ter realizado a reação em cadeia da polimerase para o parvovírus B19.

\section{REFERÊNCIAS}

1. Anderson LJ, Tsou C, Parker RA, Chorba TL, Wulff H, Tattersall P, Mortimer PP. Detection of antibodies and antigens of human parvovirus B19 by Enzyme-linked immunosorbent assay. Journal of Clinical Microbiology 24:522-526, 1986.

2. Araújo TP, Rodrigues SG, Costa MIWA, Vasconcelos PFC, Rosa APAT. Diagnóstico sorológico de infecções por dengue e febre amarela em casos suspeitos no Estado do Pará, Brasil, 1999. Revista da Sociedade Brasileira de Medicina Tropical 35:579-584, 2002.

3. Brown KE. Parvovirus B19. In: Mandell GL, Bennett JE, Dolin R (eds) Principles and Practice of Infectious Diseases, 6th edition, Elsevier Churchill Livingstone, Philadelphia, p.1891-1896, 2005.

4. Cordeiro MT, Schatzmayr, Nogueira RMR, Oliveira WF, Mello WT, Carvalho EF. Dengue and dengue hemorrhagic fever in the State of Pernambuco, Brazil, 1995-2006. Revista da Sociedade Brasileira de Medicina Tropical 40:605-611, 2007.

5. Cubel RCN, Siqueira MM, Santos EO, Pires MF, Cruz CM, Nascimento JP. Human Parvovirus B19 Infections Among Exanthematic Diseases Notified as Measles. Revista da Sociedade Brasileira de Medicina Tropical 30:15-20, 1996.

6. Davidkin I, Valle M, Peltola H, Hovi T, Paunio M, Roivainen M, Linnavuori K, Jokinen S, Leinikki P. Etiology of Measles and Rubella-like Illnesses in Measles, Mumps, and Rubella-Vaccinated Children. The Journal of Infectious Diseases 178:1567-1570, 1998.

7. Dietz V, Rota J, Izurieta H, Carrasco P, Bellini W. The laboratory confirmation of suspected measles cases in settings of low measles transmission: conclusions from the experience in the Americas. Bulletin of the World Health Organization 82: 852-857, 2004

8. Figueiredo RMP, Lima ML, Almeida TMC, Bastos MS. Presença de parvovirus B19 em Manaus, AM. Revista da Sociedade Brasileira de Medicina Tropical 38:396-398, 2005.

9. Figueiredo RMP, Thatcher BD, Lima ML, Almeida TC, Alecrim WD, Guerra, MVF. Doenças exantemáticas e primeira epidemia de dengue ocorrida em Manaus, Amazonas, no período de 1998-1999. Revista da Sociedade Brasileira de Medicina Tropical 37:476-479, 2004.

10. Fundação Nacional de Saúde. Guia de Vigilância Epidemiológica. $5^{\text {a }}$ edição. Brasília, 2002.

11. Gonçalves Neto VS, Rebêlo JMM. Aspectos epidemiológicos do dengue no município de São Luiz, Maranhão, Brasil, 1997-2002. Cadernos de Saúde Pública 20:1427-1431, 2004

12. Kerr J C. Parvovirus B19 infection. European Journal of Clinucal Microbiology \& Infectious Diseases 15:10-29, 1996.

13. Linhares MI, Eizuru Y, Tateno S, Minamishima Y. Seroprevalence of human herpesvirus 6 infection in Brazilian and Japanese populations in the north- east of Brazil. Microbiology and Immunology 35:1023-1027, 1991.

14. Ministério da Saúde. Manual de Vigilância Epidemiológica das Doenças Exantemáticas: Sarampo, Rubéola e Síndrome da Rubéola Congênita (SRC). $3^{\text {a }}$ edição. Brasília, 2003.

15. Ministério da Saúde. Coordenação Geral de Laboratórios de Saúde Pública. Avaliação do Protocolo de Diagnóstico diferencial de Doenças Exantemáticas. Abril, 2007.

16. Oliveira MI, Curti SP, Figueredo CA, Afonso AM, Theobaldo M, Azevedo RS, Durigon EL. Rash after measles vaccination: laboratory analysis of cases reported in São Paulo, Brazil. Revista de Saúde Pública 36:155-159, 2002.

17. Oliveira SA, Camacho LAB, Pereira ACM, Bulhões MM, Águas AF, Siqueira MM. Performance of rubella suspect case definition: implications for surveillance. Revista de Saúde Pública 40:450-456, 2006.

18. Oliveira SA, Camacho LAB, Pereira ACM, Faillace TF, Setúbal S, Nascimento JP. Clinical and Epidemiological Aspects of Human Parvovirus B19 Infection in an Urban Area in Brazil (Niterói City Area, state of Rio de Janeiro, Brazil). Memórias do Instituto Oswaldo Cruz 97:965-970, 2002.

19. Oliveira SA, Camacho LAB, Pereira ACM, Setúbal S, Nogueira RMR, Siqueira MM. Assessment of the performance of a definition of a suspected measles case: implications for measles surveillance. Pan American Journal of Public Health 19: 229-35, 2006 
20. Oliveira SA, Siqueira MM, Camacho LAB, Nogueira RM, Spinetti CCJ, Cubel RCN, Knowles W.The aetiology of macular rash diseases in Niterói, State of Rio de Janeiro, Brazil: implications for measles surveillance. Epidemiology and Infection 127:509-516, 2001

21. Prevots R, Parisi MS, Segatto TCV, Siqueira MM, Santos ED, Ganter B, Perreira MC, Domingues CA, Lanzieri T, Silva Jr JB. Interruption of Measles Transmission in Brazil, 2000-2001. The Journal of Infectious Diseases 187: S111-S120, 2003

22. Ramsay M, Reacher M, O'Flynn C, Buttery R, Hadden F, Cohen B, Knowles W, Wreghitt T, Brown D. Causes of morbilliform rash in a highly immunised English Population. Archives of Disease in Childhood 87:202-206, 2002.

23. Scott LA, Stone MS. Viral exanthems. Dermatology Online Journal 9:4, 2003 .
24. Seve P, Ferry T, Charhon A, Calvet A, Broussolle C. Systemic manifestations of Parvovirus B 19 infections. Revue Médecine Interne 25:740-751, 2004.

25. Shirley JA, Revill S, Cohen BJ, Buckley MM. Serological study of rubella-like illnesses. Journal of Medical Virology 21:369-379, 1987.

26. Wermelinger MC. Oelemann WM, Mendonça MCL, Naveca FG, von Hubinger MG. Detection of human parvovirus B19 infection: a study of 212 suspected cases in the state of Rio de Janeiro, Brazil. Journal of Clinical Virology 25:223-230, 2002.

27. Young NS, Brown KE. Parvovirus B19. New England Journal of Medicine 350:586-597, 2004

28. Zellman GL. Erythema Infectiosum (Fifth Disease). eMedicine instant acess to the minds of medicine. In: Krafchic BR, Vinson RP, Perry V, Quirk C, Elston DM (eds) Last Update: july 24, 2007. Disponível no site http://emedicine.com/DERM/ topic136.htm. Acesso em 25/07/2007. 